\title{
Spinal involvement in mucopolysaccharidosis IVA (Morquio-Brailsford or Morquio A syndrome): presentation, diagnosis and management
}

\author{
Guirish A. Solanki • Kenneth W. Martin • \\ Mary C. Theroux • Christina Lampe $\cdot$ Klane K. White • \\ Renée Shediac • Christian G. Lampe • Michael Beck • \\ William G. Mackenzie • Christian J. Hendriksz • \\ Paul R. Harmatz
}

Received: 10 October 2012 / Revised: 29 December 2012 / Accepted: 7 January 2013 / Published online: 6 February 2013

(C) The Author(s) 2013. This article is published with open access at Springerlink.com

\begin{abstract}
Mucopolysaccharidosis IVA (MPS IVA), also known as Morquio-Brailsford or Morquio A syndrome, is a lysosomal storage disorder caused by a deficiency of the enzyme $N$-acetyl-galactosamine-6-sulphate sulphatase (GALNS). MPS IVA is multisystemic but manifests
\end{abstract}

Communicated by: Ed Wraith

\section{G. A. Solanki $(\bowtie)$}

Department of Paediatric Neurosurgery, Birmingham Children's Hospital NHS Foundation Trust, Steelhouse lane,

Birmingham B4 6NH, UK

e-mail: guirish.solanki@bch.nhs.uk

K. W. Martin • P. R. Harmatz

Children's Hospital and Research Center Oakland,

Oakland, CA, USA

M. C. Theroux $\cdot$ W. G. Mackenzie

Alfred I. duPont Hospital for Children, Wilmington, DE, USA

C. Lampe $\cdot$ M. Beck

Children's Hospital, University Medical Center,

University of Mainz, 55131 Mainz, Germany

K. K. White

Seattle Children's Hospital, University of Washington,

Seattle, WA, USA

\section{R. Shediac}

BioMarin Pharmaceutical Inc., Novato, CA, USA

C. G. Lampe

Children's Hospital, Horst Schmidt Clinics,

65199 Wiesbaden, Germany

\section{J. Hendriksz}

University of Manchester, Manchester Academic Health Science Centre, Salford Royal NHS Foundation Trust, Manchester, UK primarily as a progressive skeletal dysplasia. Spinal involvement is a major cause of morbidity and mortality in MPS IVA. Early diagnosis and timely treatment of problems involving the spine are critical in preventing or arresting neurological deterioration and loss of function. This review details the spinal manifestations of MPS IVA and describes the tools used to diagnose and monitor spinal involvement. The relative utility of radiography, computed tomography (CT) and magnetic resonance imaging (MRI) for the evaluation of cervical spine instability, stenosis, and cord compression is discussed. Surgical interventions, anaesthetic considerations, and the use of neurophysiological monitoring during procedures performed under general anaesthesia are reviewed. Recommendations for regular radiological imaging and neurologic assessments are presented, and the need for a more standardized approach for evaluating and managing spinal involvement in MPS IVA is addressed.

\section{Introduction}

Mucopolysaccharidosis IVA (MPS IVA; OMIM 253000), also referred to as Morquio-Brailsford or Morquio A syndrome (Brailsford 1929; Morquio 1929), is an autosomal recessive lysosomal storage disorder caused by defective activity of $N$-acetyl-galactosamine-6-sulphate sulphatase (GALNS; EC 3.1.6.4), an enzyme that catalyzes the breakdown of two glycosaminoglycans (GAGs), keratan sulphate (KS) and chondroitin-6-sulphate (C6S). Over 170 mutations in the GALNS gene have been identified (http://www.hgmd.org/), giving rise to wide genotypic and phenotypic heterogeneity (Tomatsu et al 2005). The incidence of MPS IVA varies among different populations; estimates range from 1 in 76,000 live 
births in Northern Ireland (Nelson 1997) to 1 in 640,000 live births in Western Australia (Nelson et al 2003).

MPS IVA is characterized by the progressive accumulation of KS and $\mathrm{C} 6 \mathrm{~S}$ in tissues. Because $\mathrm{KS}$ and $\mathrm{C} 6 \mathrm{~S}$ are major components of proteoglycans in cartilage and bone, MPS IVA mainly manifests as skeletal dysplasia and short stature (Northover et al 1996; Tomatsu et al 2011; Wraith 1995) with bone deformity defined as dysostosis multiplex being the most common initial symptom (Montano et al 2007; Tomatsu et al 2011). The visual, auditory, cardiovascular, and respiratory systems are also compromised in this multisystemic disorder (Hendriksz et al 2012; Northover et al 1996; Tomatsu et al 2011). Although neurocognitive function is generally not believed to be affected in MPS IVA (Tomatsu et al 2011; Wraith 1995), a recent study suggests that there may be subtle neurocognitive involvement (Davison et al 2012). The onset of symptoms typically occurs prior to 1 year of age in rapidly progressing patients and generally in the second decade of life in slowly progressing patients (Montano et al 2007). For individuals with a severe phenotype, paralysis from cervical myelopathy, respiratory insufficiency, and heart abnormalities may all contribute to a shortened lifespan, with death often occurring in the second or third decade (Montano et al 2007; Tomatsu et al 2011). In contrast, patients with attenuated MPS IVA may have normal or near-normal life expectancies (Montano et al 2007; Tomatsu et al 2011).

Spinal involvement in MPS IVA occurs at two distinct sites. Cervical spinal involvement, particularly instability and compression at the C1-C2 level, is a near universal finding and predisposes patients to myelopathy, paralysis, and sudden death (Tomatsu et al 2011). Spinal cord compression due to kyphotic deformity at the thoracolumbar level is not as common, but can lead to paraplegia with insidious onset and all of its devastating consequences (Blaw and Langer 1969). Prevention of these complications requires early detection and prompt treatment of cervical instability, spinal stenosis, and spinal cord compression. Spinal involvement is usually progressive but neurological deficits can occur suddenly (Northover et al 1996). Neurological signs and symptoms may underestimate the severity of spinal cord involvement seen on magnetic resonance imaging (MRI) (Hughes et al 1997; Northover et al 1996), underscoring the importance of advanced imaging in the management of spine disease in MPS IVA. Cervical fusion and/or decompression are the most frequently performed surgical procedures in this patient population (Montano et al 2007). However, cervical instability and myelopathy, along with chest wall deformities and upper and lower airway obstruction, complicate the airway and anaesthetic management of MPS IVA patients presenting for surgery (Belani et al 1993; McLaughlin et al 2010; Morgan et al 2002; Shinhar et al 2004; Theroux et al 2012; Walker et al 1994).

With the goal of improving patient outcomes in MPS IVA, this present article reviews the complex anatomy and pathology of the atlantoaxial region of the cervical spine, provides an overview of spinal involvement in MPS IVA, describes the neurological examination, neurophysiological testing methods, and imaging modalities used to diagnose and monitor the progression of spinal involvement, discusses surgical interventions and anaesthetic considerations, and presents recommendations for regular radiologic and neurologic assessments.

\section{Anatomy and pathology of the atlantoaxial system}

Knowledge of the unique anatomy and pathology of the atlantoaxial (C1-C2) system facilitates radiological detection of upper cervical spine anomalies. Figure 1 shows the normal anatomy of the craniocervical junction. The anatomy and radiological interpretation of the atlantoaxial system are particularly complex in children because of anatomic variants and developmental changes early in life and have been well summarized by Lustrin et al (Lustrin et al 2003). The articulation of the atlas $(\mathrm{C} 1)$ with the axis $(\mathrm{C} 2)$ is complex, comprising several distinct synovial joints. The median atlantoaxial joint between the dens (odontoid process) of $\mathrm{C} 2$ and the ring formed by the anterior arch and transverse ligament of $\mathrm{C} 1$ is a pivot joint, and may be considered a double joint (Clemente 2010). Two lateral atlantoaxial joints between the lateral masses of $\mathrm{C} 1$ and $\mathrm{C} 2$ are gliding joints. The articulation of the anterior arch of $\mathrm{C} 1$ with the dens of $\mathrm{C} 2$ allows for $50 \%$ of cervical lateral rotation. Competent transverse and alar ligaments maintain the integrity of the atlantoaxial articulation by limiting posterior translation of the dens. However, incompetent ligaments or dens hypoplasia may cause excessive independent movement between the anterior arch of $\mathrm{C} 1$ and the dens to result in atlantoaxial instability. During flexion, the anterior $\mathrm{C} 1$ arch moves antero-inferiorly. Without competent ligaments to ensure that the dens follows this movement within a couple of millimetres, a relative posterior tilting of the dens occurs and could lead to compression of the cervical cord. A pincer-like effect is created by the posterior arch of $\mathrm{C} 1$ which indents the dorsal aspect of the cervical cord as it translates forwards unimpeded relative to $\mathrm{C} 2$. Abnormal $\mathrm{C} 1$ arch antero-inferior movement and posterior dens tilting can create an anterior atlanto-dens interval (ADI, the distance between the anterior arch of $\mathrm{C} 1$ and the anterior surface of the dens) in excess of $2.5 \mathrm{~mm}$ in adults and $5 \mathrm{~mm}$ in children, which is known as horizontal atlantoaxial subluxation. This may cause cervical cord compression, significant neurologic compromise and even death. Transverse ligament failure can cause the dens to move both horizontally and vertically. If the relative upwards position of the dens reaches the level of the medulla and compresses it, bulbar paralysis or death can result. This is known as vertical subluxation, cranial settling or basilar invagination. If the alar ligaments are stretched or 
Fig. 1 Normal anatomy of the craniocervical junction. a Sagittal midline graphic depicts the normal articulations and ligamentous anatomy of the craniocervical region. b Sagittal midline CT reconstruction shows the bony and ligamentous structures at the craniocervical junction. c Sagittal T2-weighted MR image of the craniocervical junction shows the bony and ligamentous components and the cervical spinal cord. Images reproduced with permission from Amirsys Publishing, Inc. (Harnsberger et al 2006)
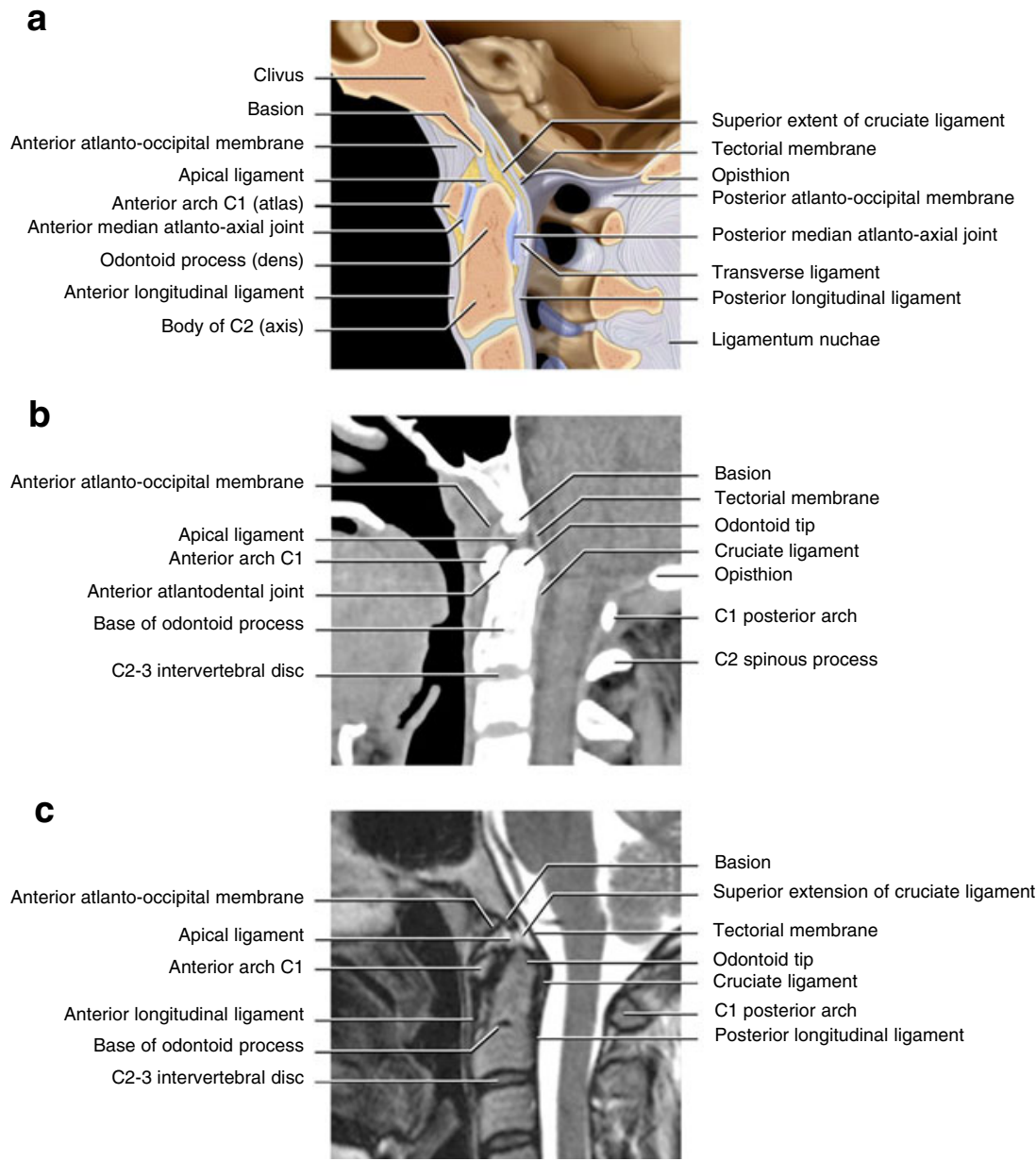

weak, increased translational movement between $\mathrm{C} 1$ and $\mathrm{C} 2$ can occur.

\section{Spectrum of spinal involvement in MPS IVA}

Bony anomalies

MPS IVA disrupts the normal development and maturation of cartilage and bone and subsequently gives rise to numerous structural anomalies of the spine (Fig. 2). Incomplete ossification of the dens is a near universal finding in MPS IVA and leads to dens hypoplasia or os odontoideum. Other spinal anomalies include generalized platyspondyly, anterior vertebral beaking, and thoracolumbar kyphosis, all represented by the term "dysostosis multiplex" (Lachman 2007).

Cervical spine subluxation and instability

Atlantoaxial (C1-C2) subluxation can occur anteriorly, posteriorly, vertically, laterally, or in combinations. Lateral x-rays taken in extension and flexion are typically used to demonstrate atlantoaxial subluxation (Fig. 3a). Atlantoaxial instability is a common finding in MPS IVA and is thought to arise from a combination of dens hypoplasia and ligamentous laxity. Only one case of cervical spinal cord compression without dens hypoplasia has been reported (Shukla et al 2011). In the presence of atlantoaxial instability, acute injury to the cord may result from sudden and/or vigorous hyperflexion or hyperextension. Chronic injury to the cord follows repetitive minor trauma in the environment of instability and stenosis. Sudden death or severe neurological damage may occur as a result of a fall or whiplash injury. Horizontal atlantoaxial subluxation in the presence of cervical spinal canal stenosis places the spinal cord at even greater risk for injury. An ADI greater than $5 \mathrm{~mm}$ is considered abnormal at any age, and when it differs by more than $2 \mathrm{~mm}$ on flexion and extension lateral radiographs, there is cervical instability. If this articulation is obscured, the spinal canal can be measured between the posterior surface of the dens of $\mathrm{C} 2$ and the posterior arch of $\mathrm{C} 1$ (the posterior atlantodens interval, or PADI) (Fig. 3a). In adults, a PADI less than $14 \mathrm{~mm}$ is indicative of cord compression (Boden et al 1993) and a difference of more than $2 \mathrm{~mm}$ on flexion and extension implies instability. Subaxial (C3-C7) instability is present with greater than $3.5 \mathrm{~mm}$ of subaxial vertebral malalignment and movement in flexion-extension dynamic image. 

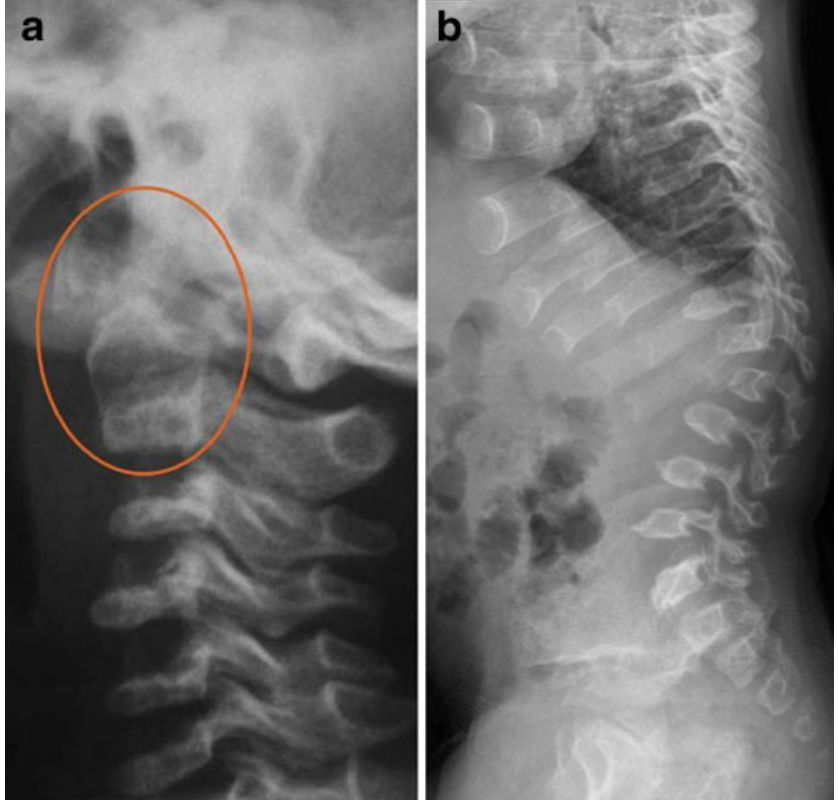

Fig. 2 Spine radiographs demonstrating the manifestations of MPS IVA. a Lateral view of the cervical spine shows a cone-shaped hypoplastic dens, which may be associated with upper cervical spine instability. The unossified cartilage cap is inapparent. The posterior arch of $\mathrm{C} 1$ is small, but thickened, resulting in spinal stenosis. b Typical thoracolumbar spine changes including platyspondyly, anterior beaking, thoracolumbar kyphosis, posterior vertebral scalloping, and broadened ribs

\section{Spinal canal stenosis}

Stenosis of the spinal canal may be diffuse (multi-segmental) or focal (segmental). Stenosis is classified as central, lateral recess or circumferential whether it is focal or diffuse. Diffuse stenosis is the combined result of multi-segmental thickening of the connective tissues within the bony spinal canal, particularly of the posterior longitudinal ligament and ligamentum flavum. Bulging discs also play a role, particularly at the thoracolumbar region. Diffuse stenosis is most likely to result in spinal cord compression at the brachial expansion (C4-C7) and at the conus medullaris (T10-L1), all levels where the cord is normally at its thickest. Generalized thickening of the posterior longitudinal ligament and the ligamentum flavum due to GAG deposition are therefore the main contributors to diffuse cord compression.

Focal stenosis occurs for specific reasons at certain levels. In the craniocervical junction, the membrana tectoria and the apical and occipito-atlantal ligaments may be thickened causing focal compression. In the axial spine, the cord at the $\mathrm{C} 1$ $\mathrm{C} 2$ level is at particular risk, ventrally by localized thickening of the peri-odontoid tissue and transverse atlantoaxial ligament (Ashraf et al 1991; Müller-Forell et al 2007) (Fig. 3b), and dorsally due to a short narrow $\mathrm{C} 1$ posterior arch or anterior translation of the posterior arch of C1 (Fig. 4b). In the sub-axial spine (C3-C7), focal stenosis may also occur at bulging discs, especially when associated with deposition of
GAGs over the posterior longitudinal ligament and the ligamentum flavum. Here the cervical spine tends to over-extend probably to avoid cord compression. Focal stenosis may also occur at the thoracolumbar junction and upper thoracic spine, which are prone to kyphosis. This is in part due to the transition from the more stable rigid thoracic cage to the more flexible cervical or lumbar spine (Fig. 4c). The additional compressive load at these boundary zones occurring during flexion can result in wedge compression deformity, especially at the L1 level (Fig. 2b).

An anteroposterior (AP) spinal canal diameter that is less than $14 \mathrm{~mm}$ is associated with cervical stenosis at any segment (Kessler 1975). A spinal canal diameter: vertebral body diameter ratio (or Torg ratio) of less than 0.8 has been used as a measure of cervical stenosis (Torg et al 1997) but may not be applicable in MPS IVA children due to vertebral platyspondyly. There is currently no standard anatomical measure to define stenosis for the thoracolumbar spine.

Because MRI demonstrates the spinal cord and spinal canal directly, it is the most useful technique in diagnosing stenosis and cord compression in the spine. As imaging technologies continue to evolve, novel anatomic measures of spinal stenosis are being investigated (e.g. ratio of the diameters of the spinal canal and spinal cord; cross-sectional area and volume of the spinal cord). Flexion-extension MRI of the cervical cord is becoming an essential technique for clinical surveillance and pre-surgical planning. When performed under anaesthesia, careful monitoring by the anaesthesiologist and close supervision by the radiologist is necessary to ensure a safe diagnostic examination (Mackenzie et al 2013). Incremental degrees of flexion and extension with short imaging sequences may optimally demonstrate instability and its impact on the spinal cord.

\section{Spinal cord compression}

In MPS IVA, spinal cord compression may occur in the upper cervical, cervicothoracic, and thoracolumbar regions (Blaw and Langer 1969; Dalvie et al 2001; Holte et al 1994; Hughes et al 1997; Lachman 2007; Stevens et al 1991) (Fig. 4). Aetiological factors include ligamentous thickening resulting from accumulation of GAGs and fibrocartilaginous tissue, cervical instability, cartilaginous and ligamentous hypertrophy at the atlantoaxial joint, thickening of the posterior longitudinal ligament in the sub-axial spine and in the thoracic and lumbar spine, acquired central canal stenosis, disc protrusion, and thoracolumbar kyphosis (Ashraf et al 1991; Dalvie et al 2001; Holte et al 1994; Hughes et al 1997; Ransford et al 1996; Stevens et al 1991). A stenotic spinal canal or a combination of stenosis and instability may be predictive of spinal cord compression, although direct measurement by MRI is necessary to confirm compression, judge severity, and identify the presence of cord injury. 

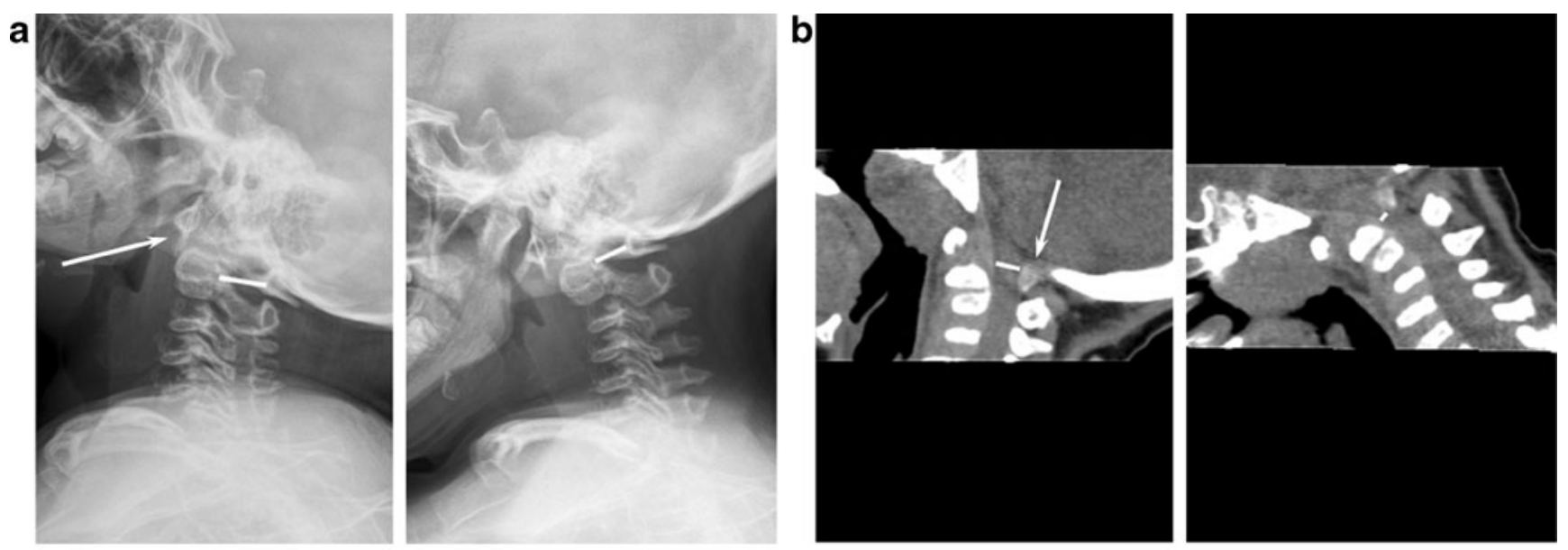
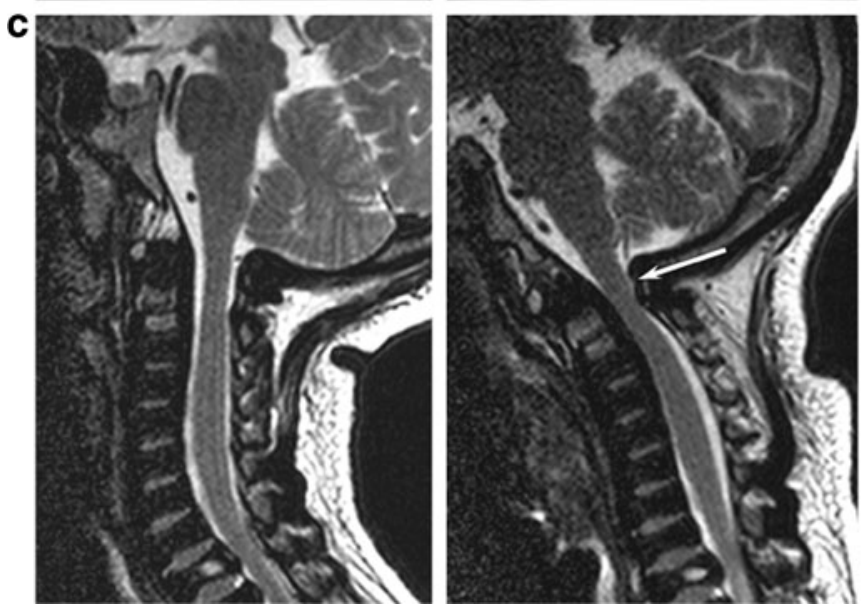

Fig. 3 Assessing cervical instability. Cervical flexion-extension lateral radiographs in (a) can be difficult to interpret. The pre-dental space is obscured by delayed ossification of the dens and superimposition of the mastoid processes (arrow). Measuring the spinal canal at C1-2 between the base of the odontoid process of $\mathrm{C} 2$ and the posterior arch of $\mathrm{C} 1$ is preferred (white lines). Flexion-extension CT with sagittal reformation and soft-tissue filtration in (b) shows the cone-shaped

Spinal stenosis with concomitant loss of cerebrospinal fluid (CSF) flow on MRI signifies spinal cord compression. If left untreated, compression can lead to cord damage and myelopathy (Fig. 5).

\section{Diagnostic and monitoring tools}

\section{Neurological examination}

The neurological examination is intended to identify patients at early stages of spinal cord compression and to monitor patients for progression of spinal cord injury. The high cervical and thoracolumbar spine are the two major locations of spinal cord compression in these patients. The main signs and symptoms suggest an upper motor neuron lesion. dens, a thickened cruciate ligament, and small thick cartilaginous posterior arch of $\mathrm{C} 1$ (arrow). With flexion, there is narrowing of the canal between the body of $\mathrm{C} 2$ and the cartilaginous posterior arch of $\mathrm{C} 1$ (white lines). T2 TSE sagittal flexion-extension MR has the advantage of imaging the spinal canal and cord directly. As shown in (c), there is spinal stenosis and flexion instability sufficient to compress the cervical cord at C1-2 (arrow)

The earliest complaints of the patient with upper cervical compression are loss of endurance, diminished walking distance and gait instability (Beighton and Craig 1973; Houten et al 2011; Kopits 1976; Northover et al 1996). Loss of strength is sometimes difficult to assess at this early stage of disease because of joint hypermobility. Findings from the neurological examination may include increased deep tendon reflexes, raised muscle tone and pyramidal tract signs such as ankle clonus and Babinski sign (Blaw and Langer 1969; Houten et al 2011; Kopits 1976). In our experience, motor signs tend to be more severe in lower extremities, but the upper extremities may be affected as well. Sensory loss is usually not profound, and loss of vibration sense and deep sensation predominate (Blaw and Langer 1969).

Compression at the thoracolumbar level causes similar symptoms as those described for high cervical compression, 

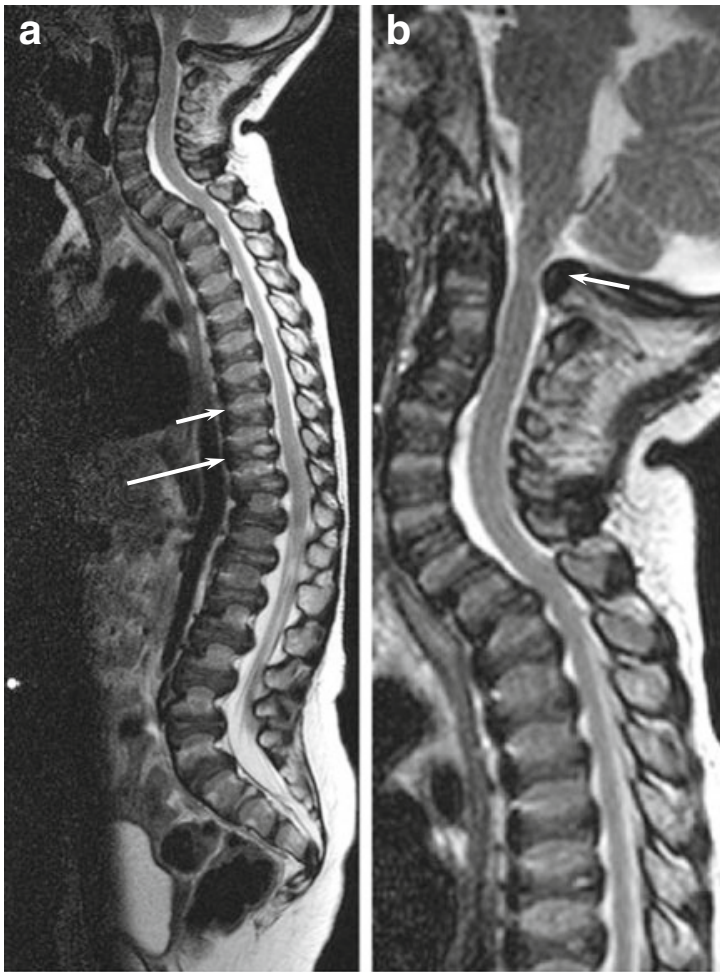

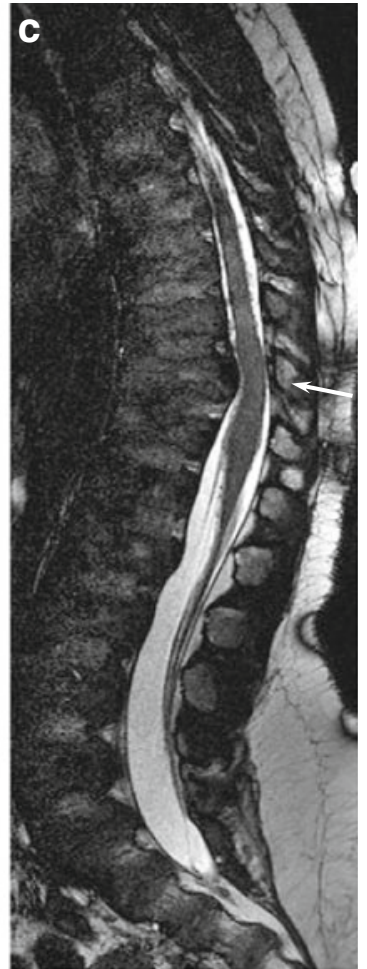

Fig. 4 Initial MRI studies should include screening of the whole spine. In (a) T2 TSE sagittal MR shows intermediate signal in flattened vertebral bodies (short arrow) separated by hypointense bulging discs (long arrow). Typical cervical lordosis, cervicothoracic and thoracolumbar kyphosis, and multiple areas of spinal stenosis are present. Smaller field-of-view imaging optionally characterizes areas of stenosis as shown by T2 TSE sagittal MR at C1-2. In (b) delayed ossification of the odontoid process of $\mathrm{C} 2$ and the small thickened posterior arch of $\mathrm{C} 1$ are present with dorsal cord compression (arrow). In (c) bFFE sagittal MR of the thoracolumbar kyphosis shows a bulging disc at T11 causing ventral compression of the conus medullaris (arrow). Dephasing of accelerated CSF causing signal loss is present dorsal to the cord at the stenosis but are confined to the legs. A major challenge is the definition of the responsible level in patients when multisegmental myelopathy secondary to cervical and thoracolumbar cord compression coexist. The most important clinical sign in these cases is the finding of a specific level of superficial sensory loss, usually the lowest part of the thoracic spinal cord (Blaw and Langer 1969) and sparing of the arms. Neurophysiology can be helpful at defining this level of injury (see Neurophysiological examination section).

\section{Imaging techniques}

The goals of neural axis imaging in MPS IVA are to detect treatable spinal cord compression, to stratify risk to the spinal cord prior to permanent loss of function, to assist in surgical planning, and to assess the efficacy of surgical and medical treatment. Systematic and careful imaging of the spine begins with plain radiographs, includes instability imaging, may require computed tomography $(\mathrm{CT})$, and generally is not complete until the spinal cord is imaged directly by MRI (Figs. 2, 3, 4 and 5). Only then does a complete diagnostic profile emerge that, combined with clinical and physiological tools, leads to comprehensive risk assessment and stratification.

Knowledge of the pathophysiology of spinal involvement in MPS IVA influences the usage of all imaging modalities. Each technique must be optimized for the specific purpose of detecting spinal cord compression or instability, and the strengths and limitations of each modality must be considered within the imaging algorithm (Table 1). Both plain radiography and CT utilize ionizing radiation. The subsequent cancer risk from exposure to radiation in the microsievert to millisievert range is negligible compared to the immediate risk of spinal cord injury and justifies the diligent application of these techniques. Careful adjustment of CT imaging technique suitable to bone, especially in paediatric patients, can reduce exposure from $67-90 \%$ when compared to traditional brain and spine imaging. Once the initial imaging evaluation of the spine is complete, subsequent imaging of the spinal cord can be limited to MRI. CT, and especially MRI, may require procedural sedation or anaesthesia. In this patient population, the risk of sedation and anaesthesia is substantially greater than in unaffected individuals. Meticulous attention to sedation or anaesthetic 
Fig. 5 Myelomalacia is best depicted by T2-weighted MR obtained in the sagittal and axial planes where an increase in $\mathrm{T} 2$ signal, coupled with volume loss in regions of cord compression, is diagnostic of myelomalacia. When T2 hyperintensity is present without atrophy, the differential diagnosis would include edema due to contusion or microvascular injury. These changes may be more apparent following surgical decompression. In (a), there is chronic T2 hyperintensity and little or no atrophy, indicating mild-to-moderate injury. With more severe cord injury, as shown in (b), there is T2 hyperintensity and focal atrophy. Postoperative T2 TSE axial and sagittal MR images show central grey matter involvement in both examples (arrows)
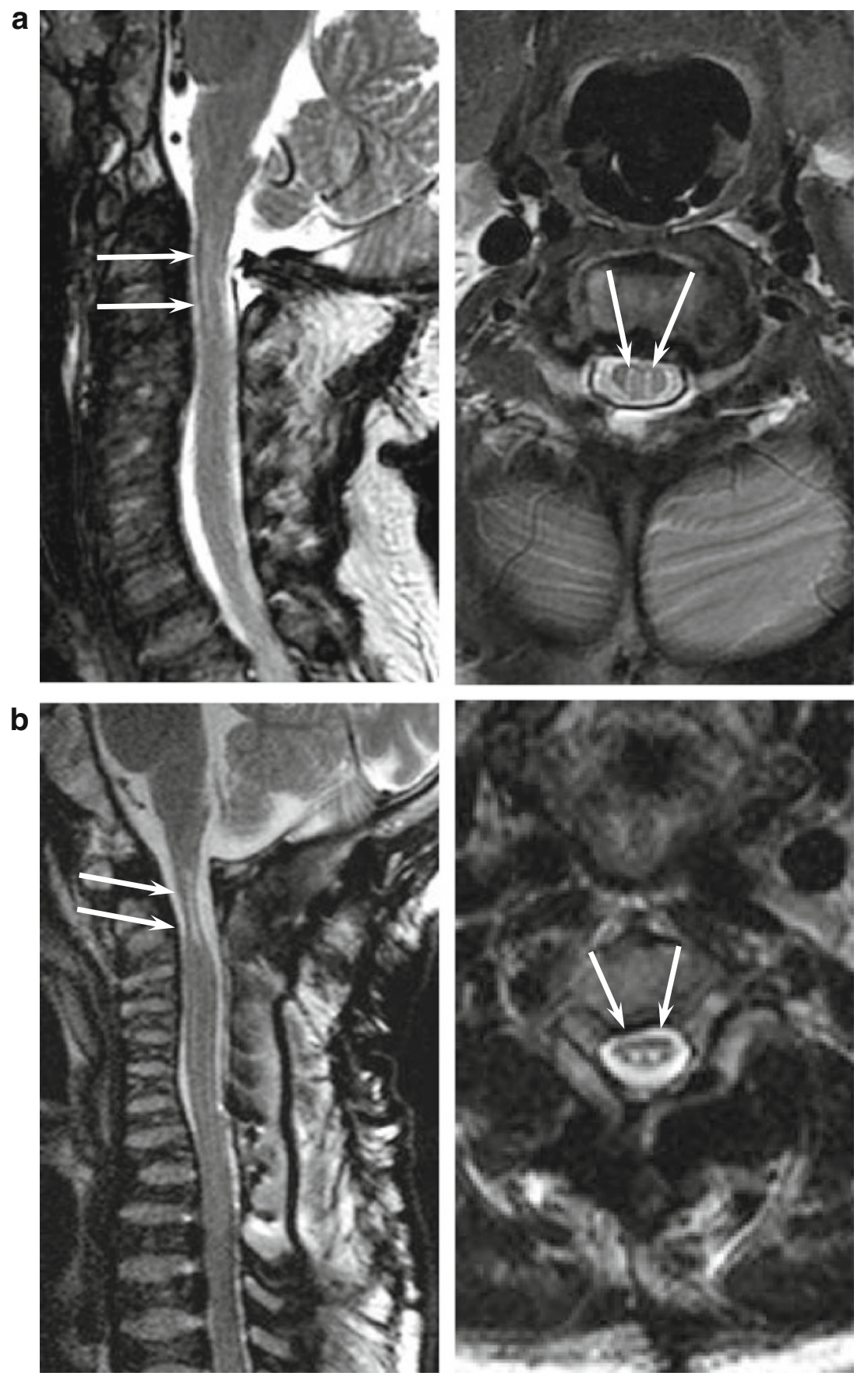

technique by individuals knowledgeable in this disease is desirable.

\section{Radiography}

Frontal and lateral radiographs of the spine are typically included in the initial imaging evaluation of suspected or diagnosed MPS IVA (Fig. 2). Detection of dysostosis, bony spinal stenosis, kyphosis, scoliosis, and vertebral body malformation are all possible with standard thoracolumbar radiographic technique. Dedicated lateral radiographs of the cervical spine provide for improved positioning and diagnostic accuracy at the craniocervical junction. Delayed ossification of the dens in children and failure to recognize the surrounding dysplastic cartilage will result in underestimation of the true size of the dens and its contribution to spinal stenosis. The addition of cervical flexion-extension lateral views is especially important for the detection and quantification of instability. Unfortunately, the presence of basilar invagination and enlarged mastoid processes often obscures the C1-C2 level. Difficulty in visualizing the spinal canal, the dens of $\mathrm{C} 2$, and the predental space between the dens 
Table 1 Comparison of radiography, CT and MRI for the evaluation of spinal involvement in MPS IVA

\begin{tabular}{|c|c|c|}
\hline & Strengths & Limitations \\
\hline Radiography & $\begin{array}{l}\text { - Assess bone malformation } \\
\text { - Assess spinal canal stenosis } \\
\text { - Assess malalignment } \\
\text { - Flexion-extension instability } \\
\text { - Rapid } \\
\text { - Inexpensive }\end{array}$ & $\begin{array}{l}\text { - Poor soft tissue discrimination } \\
\text { - Limited by overlapping structures } \\
\text { - Ionizing radiation } \\
\text { - Limited to ossified structures }\end{array}$ \\
\hline $\mathrm{CT}$ & $\begin{array}{l}\text { - Rapid (may obviate need for anaesthesia) } \\
\text { - Multiplanar imaging of bony structures } \\
\text { - Alternative method for assessing flexion-extension instability in difficult } \\
\text { cases (recommend low radiation dose protocol }{ }^{\mathrm{a}} \text { ) } \\
\text { - Can assess some soft tissue components of canal stenosis and cord } \\
\text { compression with appropriate filtering } \\
\text { - Preoperative planning }\end{array}$ & $\begin{array}{l}\text { - Suboptimal for visualizing soft tissues } \\
\text { and the spinal cord } \\
\text { - Ionizing radiation } \\
\text { - More expensive and less accessible } \\
\text { than plain film radiography }\end{array}$ \\
\hline MRI & $\begin{array}{l}\text { - Multiplanar imaging } \\
\text { - Ideal for soft tissue imaging } \\
\text { - Preferred method for assessing spinal cord compression and myelomalacia } \\
\text { - Flexion-extension imaging directly visualizes spinal cord } \\
\text { - Demonstrate venous collaterals } \\
\text { - Non-ionizing radiation }\end{array}$ & $\begin{array}{l}\text { - Long imaging times } \\
\text { - May require anaesthesia } \\
\text { - Metal and motion artifacts } \\
\text { - Limited access } \\
\text { - Expensive }\end{array}$ \\
\hline
\end{tabular}

${ }^{\mathbf{a}}$ Focus on area of interest only, with lowest possible dose technique to yield adequate signal-to-noise at bone algorithm displayed at bone window

and the anterior arch of $\mathrm{C} 1$ can severely limit the usefulness of this modality in many patients. This is especially true when attempting to measure flexion-extension instability at $\mathrm{C} 1-\mathrm{C} 2$. When the anterior atlantoaxial articulation is obscured, the traditional method of measuring change at the predental space (ADI) is not possible. Measuring the change in AP diameter of the spinal canal between the posterior surface of the dens of $\mathrm{C} 2$ and the posterior arch of $\mathrm{C} 1$ (PADI) can quantify instability and provide a direct measurement of the spinal canal AP diameter (Fig. 3a). It is possible to crudely infer spinal cord compression by detecting a stenotic spinal canal or by demonstrating a combination of stenosis and instability. No degree of instability can be viewed as normal if the canal is stenotic and the cord is compressed when the spine is in neutral position. The correction of instability in addition to relief of cord compression due to stenosis is contingent upon accurate characterization of the dens, detection of an unstable os odontoideum, and accurate measurement of flexion-extension translation.

\section{CT}

Cross-sectional imaging provides improved visualization of complex structures. This is true for the cervical spine where, in the setting of trauma, CT scanning has become the imaging method of choice to exclude fracture or malalignment. If CT scanning is performed properly, it is possible to assess both the bony and soft tissue structures of the spine. CT has the advantage of speed over MRI and can be used when cooperation may be limited, but sedation is not desirable. $\mathrm{CT}$ enables accurate measurement of the bony spinal canal as well as detection of the soft tissue component of spinal stenosis when proper imaging filters and scanning technique are utilized. Accurate measurement of bony structures, such as pedicles, may be performed for surgical planning and anticipating hardware requirements. Multiplanar reformations including in the sagittal plane are critical for cervical imaging, particularly for characterization of the dens and atlantoaxial articulation. Retroflexion of the dens, an os odontoideum, hypoplasia of the $\mathrm{C} 1$ posterior arch, and ligamentous hypertrophy are easily demonstrated in the neutral sagittal plane. Voluntary flexion-extension CT scanning can be performed in seconds to minutes while awake patients can monitor their own condition. Positioning is accomplished by placing sponges or pillows under the head or shoulders to achieve flexion or extension as desired. Limited scanning of the area of interest, usually $\mathrm{C} 1-\mathrm{C} 2$, can be achieved with dosage control to minimize exposure. In sedated patients, CT offers some advantages in speed over MRI for static flexion-extension imaging. When necessary to perform CT at an early age, it is possible using appropriate bone and soft tissue filters to demonstrate dysplastic cartilage of the dens surrounding the delayed central ossification nucleus. By including the contribution of 
cartilage, this results in a more accurate assessment of the contribution of the dens to cervical spinal stenosis. While MRI is clearly the method of choice for soft tissue imaging, careful attention to slice thickness and image filtration can produce images of diagnostic quality for assessing spinal canal stenosis due to either bony or soft tissue components (Fig. 3b). CT, however, does not offer the ability to assess the health of the spinal cord itself. The detection of canal stenosis, cord compression, and myelomalacia are important points along the course of disease progression. Spinal cord health and detection of myelomalacia are the domain of MRI.

\section{MRI}

MRI is the single most useful method for evaluating the neural axis in MPS IVA and is currently considered the imaging method of choice for evaluating the spinal cord (Fig. 4). No other imaging method provides superior information about the soft tissues, including the cartilage, ligaments, dura, spinal cord, and nerve roots. The minimum scan should include $\mathrm{T} 1$ and $\mathrm{T} 2$ weighted sequences obtained in the axial and sagittal planes. Imaging the entire spinal canal is important with coverage from the posterior fossa to the mid sacrum. Dedicated head and spine coils provide the highest quality images. Specialized imaging sequences can be applied as required to fully evaluate and stage areas of stenosis and potential cord compression. Some sites are now performing dynamic flexion-extension MRI to assess instability (Fig. 3c). When performed under sedation or anaesthesia, this method should be used with careful attention to patient safety (Mackenzie et al 2013).

Basic T1 and T2 weighted sequences should be assessed for alignment of the spine, anomalies and dysplasia of the dens, hypoplasia of $\mathrm{C} 1$, ligamentous hypertrophy, spinal stenosis, cord compression, and myelomalacia (Fig. 5). With the objective of identifying spinal cord risk prior to development of permanent loss of function, it is ideal to monitor the scan while in progress. Because anaesthesia carries a higher risk for MPS IVA patients, simply having patients return at a later date for additional imaging should be avoided. There should be a diligent application of advanced imaging methods as needed to immediately resolve questions regarding cord contact, compression, or development of myelomalacia.

\section{Specialized MRI sequences}

There are some limitations associated with conventional MR imaging of the spinal cord. For example, hypertrophied ligaments and dura are typically dark on T2 weighted images, and accelerated CSF flow can cause loss of T2 signal in the CSF so that dark fluid and dark ligaments can be indistinguishable. Selective application of advanced imaging methods helps to resolve such issues.

i. Cisternography: It is possible to image CSF directly using a technique known as steady state free precession (SSFP). This sequence is available from major manufacturers including Philips (BFFE), Siemens (CISS), and General Electric (FIESTA). The very short excitation and repetition times typical of these sequences, which are in the 5 to 10 millisecond range, allow us to "freeze" moving CSF. This is analogous to using a high shutter speed on a $35 \mathrm{~mm}$ camera. The darkening effects of rapidly moving fluid are suppressed, but not completely eliminated. When acquired in the sagittal plane, the spinal canal can be imaged with $0.5 \mathrm{~mm}$ resolution in 3 to $4 \mathrm{~min}$ (Fig. $4 \mathrm{c}$ ). This sequence is especially useful for detecting CSF around the cord, but is also superb at demonstrating the roots of the cauda equina.

ii. CSF flow imaging: The pulsatile movement of CSF through the ventricles, over the brain, and around the spinal cord is a direct consequence of blood flow into the cranial vault with every cardiac cycle. As blood enters during systole, there is a delay in venous outflow which results in bulk movement of CSF to maintain constant intracranial volume. Movement of fluid can be detected using a method known as phase contrast imaging. Rather than causing a loss of signal and darkening of the image, we rely on the movement of fluid to create contrast on the image. By timing or "gating" the image to the cardiac cycle, a movie is created representing a single cardiac cycle. When obtained in the sagittal plane at the foramen magnum and upper cervical cord, pulsatile movement of fluid can be detected. The absence of fluid pulsation anterior and posterior to the cervical cord implies effacement of the CSF space and cord contact. The cervical cord itself may demonstrate pulsatility and bulk movement within the narrowed canal. If fluid cannot move, then pulsation of the cord up and down the canal results. This may contribute to cord injury through development of syringomyelia or possibly microcontusion.

iii. Diffusion weighted imaging (DWI): Once contact with the cord occurs and there is complete effacement of CSF, any further narrowing of the canal results in tissue compression. Distinguishing contact from compression is important in risk stratification. Demonstrating altered diffusion within the cord may be a method to detect compression and impending myelomalacia prior to alteration of T1 or T2 signal intensity. Acute cord compression might cause diffusion restriction, while chronic compression would cause increased diffusivity. Whether these changes are reversible and can be detected prior to 
development of permanent cord injury and myelomalacia remains to be determined. The application of DWI to the spinal cord poses technical challenges due to susceptibility and movement artifacts. Imaging a thin compressed cord in a child can be uniquely challenging, and optimal imaging techniques are still in the development phase. iv. Diffusion tensor imaging (DTI): Rather than displaying net diffusion magnitude, as in diffusion weighted imaging, diffusion tensor imaging calculates three separate $x, y$, and $z$ vector components of diffusion. The largest component is called the major vector and the two remaining are called the minor vectors. The degree to which the summed vectors depict elliptical rather than spherical diffusion can be calculated as fractional anisotropy (FA) values. The highly structured movement of water along myelinated fibres in the spinal cord is associated with high FA values. As damage to the cord occurs with compression or contusion, there is a loss of structured movement and a decrease in measured FA values. In the end stage of myelomalacia, the diffusion of water becomes nearly spherical, while total diffusion increases. Detection of these changes in the orderliness of diffusion may be a sensitive method to detect impending cord injury due to compression. An additional benefit of DTI is that DWI can be calculated from the same raw data; importantly, those images suffer from fewer artifacts than conventionally acquired DWI. Finally, fibre tractography is possible with DTI. Termination or diminution of virtual fibres in regions of cord compression may indicate axonal injury and gliosis. Unfortunately, DTI of the cord obtained in the axial plane is time-consuming. The technique is best applied to areas of suspected compression, rather than used as a screening technique for the entire cord.

v. Spectroscopy: Proton spectroscopy of the cord should detect injury by demonstrating a decrease in the neuronal marker $\mathrm{N}$-acetylaspartate or an increase in the glial marker myo-inositol. While this seems simple enough in theory, practical MR spectroscopy of the spinal cord poses several challenges, including fat and water suppression, motion suppression, spatial resolution, and diminished signal. All these factors conspire to degrade signal-to-noise ratios. Recent progress in MR spectroscopy has been made in the setting of cord injury which encourages us to continue to refine and adapt this imaging method, the hope being to detect evidence of injury in the absence of other imaging abnormalities.

vi. Venography: Because foramina at the skull base are small in MPS IVA individuals, intracranial venous hypertension can occur due to obstruction of outflow at the jugular foramina. Transcalvarial collaterals develop to provide drainage. These collateral veins can be especially dense in the suboccipital region. When surgical intervention is planned, identification of these veins may be helpful to the surgeon. Non-contrast MR venography performed with phase technique similar to CSF flow imaging is the preferred method.

Neurophysiological examination

Neurophysiologic studies using somatosensory evoked potentials (SSEPs) of the median nerve have been reported to be helpful in diagnosing and monitoring cervical cord compression in MPS VI (Horovitz et al 2011). However, data regarding the value of electrophysiology in diagnosing or monitoring spinal cord compression in MPS IVA are scarce. In a study of 15 MPS patients (eight with MPS IVA), a correlation between pathological SSEP of the median nerve and clinical findings was found, but the SSEP of the median nerve did not predict spinal cord compression as determined by MRI (Boor et al 2000). Furthermore, SSEP of the posterior tibial nerve added little information. Möllmann et al could not find a correlation between neurological examination and SSEP of the median nerve in 22 patients with MPS IVA, 12 of whom received cervical decompression surgery (Möllmann et al 2012). To date, there are no systematic studies of the value of electrophysiological examinations in diagnosing and monitoring spinal cord compression below the cervical spine. However, by comparing SSEPs of the median and the posterior tibial nerves, it is possible to discriminate between lesions at the level of the craniocervical junction and below the lower cervical spinal cord (Lampe, unpublished data).

There are currently no data regarding the value of motor evoked potentials (MEP) in determining spinal cord compression at the craniocervical junction or other locations in patients with MPS IVA. At this time, we cannot recommend SSEP studies to diagnose or monitor progression of spine compression or injury in MPS IVA. These techniques should be used in experienced centres as part of research protocols to improve our understanding of their possible value as clinical tools.

\section{Other diagnostic examinations}

A number of specialized exams may be used to indicate spinal cord compression and loss of function. Sleep studies indicating central apnoea suggest possible injury to the brain stem. Urodynamics demonstrating neurogenic bladder may provide additional support for progressive and significant spinal cord injury. Functional testing such as the 6 min walk test (McDonald et al 2010) may also provide the first indication of spinal cord injury if it has been completed regularly over a long time period and a decrease in function is noted. 


\section{Management of the spine in MPS IVA}

Recommended assessments

MPS IVA requires a multidisciplinary approach to patient care. Close collaboration between clinicians and radiologists is essential to prevent progressive spinal and neurological deterioration in MPS IVA patients. To evaluate the severity of spinal involvement and monitor its progression, the following assessments are recommended at the time of diagnosis and at regular intervals thereafter:

- Neurological examination

- MRI screening of the entire spine with special attention to the craniocervical junction

- AP and lateral cervical radiographs (including flexionextension) or $\mathrm{CT}$ if required

- MRI flexion-extension studies if indicated

- Whole spine radiograph when clinically indicated for scoliosis/kyphosis deformity of the thoracolumbar region

Continuous neurological and radiological monitoring is strongly urged to ensure optimal patient outcomes. In the absence of established guidelines, determination of the type and frequency of assessments for a particular patient should be guided by factors that include disease severity, age and evidence of instability, cord compression, or neurological deficit. A recommended schedule of assessments is proposed in Table 2; however, we recognize that institutional and local practices may require deviation from these recommendations.

\section{Surgical interventions}

Indications for surgery include the development of pathological reflexes and neurological deficits on neurological examination with instability, or cord compression with signal change on MRI (even without symptoms). Patients with MPS IVA are difficult to assess neurologically due to their lower limb joint involvement which makes power and deep tendon assessment unreliable. The addition of serial functional assessment findings using walk tests, sleep studies or urodynamics enables more reliable determination of progression and neurological status. Rarely, some patients may develop intractable neck and head pain requiring intervention. Other indications for surgery are less clear; prophylactic fusion and/or decompression at an early age have been recommended by some (Lipson 1977; Ransford et al 1996).

The overall goals for spinal surgery are to protect the spinal cord, relieve neural compression, eliminate instability, reduce deformity or malalignment, and relieve pain. Cervical C1-C2 subluxation causes cord compression resulting in myelopathy. In the thoracic or lumbar spine, where spinal stenosis is associated with kyphosis and typically occurs without instability, relief of cord compression and correction of alignment are the main treatment goals. However, it is important to ensure that decompression will not lead to future instability by removal of posterior supporting elements and destabilization of the middle and posterior spinal columns.

Surgical procedures vary across institutions. In general, the extent of surgery and surgical approach are dictated by the presence and degree of cervical instability, the site of

Table 2 Recommended assessments for diagnosing and monitoring spinal involvement in MPS IVA patients

\begin{tabular}{|c|c|c|}
\hline Assessment & At diagnosis & Frequency $^{\mathrm{a}}$ \\
\hline Neurological examination & Yes & 6 months \\
\hline Plain radiography cervical spine (AP, lateral neutral and flexion-extension) ${ }^{\mathrm{b}}$ & Yes & $2-3$ years \\
\hline Plain radiography spine (AP, lateral thoracolumbar) & Yes & 2-3 years if evidence of kyphosis or scoliosis \\
\hline MRI neutral position, whole spine ${ }^{\mathrm{c}}$ & Yes & 1 year \\
\hline Flexion-extension of cervical spine by MRI $\mathrm{I}^{\mathrm{c}, \mathrm{d}, \mathrm{e}}$ & Yes & $1-3$ years \\
\hline CT neutral region of interest & & Preoperative planning \\
\hline
\end{tabular}

${ }^{a}$ Additional examinations may be necessary before surgical procedures or if there have been no recent examinations

${ }^{\mathrm{b}}$ If plain x-rays are technically inadequate then CT neutral and flexion/extension, usually done without anaesthesia, may be considered for the evaluation of instability

${ }^{\mathrm{c}}$ MRI evaluation may require intravenous or general anaesthesia, which carries substantial risk for MPS IVA patients. Risk may be reduced by minimizing examination times, using continuous neurophysiological monitoring, and performing these examinations in experienced MPS treatment centres with neurosurgical oversight and experienced anaesthetic cover

${ }^{\mathrm{d}}$ MRI flexion-extension sequences can be obtained if flexion-extension radiographs are abnormal or inconclusive or when stenosis on MRI is present

${ }^{\mathrm{e}}$ Mackenzie et al 2013 
cord compression, the number of levels affected, and the associated clinical picture.

\section{Axial spine}

When atlantoaxial subluxation is associated with severe instability, a posterior cervical fusion is recommended to eliminate pathological movement and stabilize the spine (Ain et al 2006). As there is often a craniocervical junction compression (C1 posterior arch may lie either at or within the foramen magnum) and the $\mathrm{C} 1$ or $\mathrm{C} 2$ bony elements are often inadequate for fixation, surgeons will favour an occipitocervical fixation and posterior fusion for $\mathrm{C} 1-\mathrm{C} 2$ subluxation and instability. If there is compression at the foramen magnum, then posterior resection of the foramen magnum rim may be required (this bone can be used as graft). The fixation may need to be extended to the subaxial segments as often the vertebral artery groove is too large to permit a C2 lateral mass or transarticular screw placement (Madawi et al 1997; Solanki and Crockard 1999; Solanki et al 1996). Often an external orthotic device such as a halo ring and vest immobilization is required starting prior to or at surgery for a period of 3 months.

The techniques for fixation vary considerably. Instrumentation in the upper cervical spine has changed substantially in the past two decades. Previous stand-alone wiring techniques like Brooks or Gallie's fusion (Brooks and Jenkins 1978; Gallie 1939) have been made largely obsolete with the development of occipital plating, transarticular screws of Magerl (Ahmed et al 2008; Claybrooks et al 2007; Elgafy et al 2010; Goel 2004; Gunnarsson et al 2007; Haid 2001; Henriques et al 2000; Lee et al 2010) and $\mathrm{C} 1$ lateral mass screws, as well as $\mathrm{C} 2$ pedicle, pars, and translaminar screws. Polyaxial screws and segmental fixation are more user-friendly than stand-alone wiring and provide a stronger construct (Bransford et al 2011). In a recent study of instrumentation of the $\mathrm{C} 2$ vertebra using the freehand technique for insertion of pedicle, intralaminar and pars screws, a high success rate with no critical violations was obtained for the placement of pedicle and intralaminar screws while pars screw insertion was found to be less reliable (Helgeson et al 2011). The surgeon needs to be aware of the complex anatomy around the pars and the vertebral artery groove. More recently the Harms technique of C1-C2 fixation (Harms and Melcher 2001) has gained popularity as it allows in-situ reduction of C1-C2 subluxation in most cases and avoids a laminar decompression.

Posterior occipito-cervical fixation and fusion of $\mathrm{C} 1-\mathrm{C} 2$ with instrumentation and bone graft is the most common approach, but metal fixation may sometimes not be feasible in the very young and in severe anomalous anatomy. It can successfully treat symptomatic atlantoaxial instability in many cases (Ahmed et al 2008; Claybrooks et al 2007).
Cervical laminectomy for decompression of the axial cervical spine may also be performed. Although intuitively the presence of preoperative $\mathrm{C} 1-\mathrm{C} 2$ subluxation or instability would argue against simple posterior column resection, immediate good results have been obtained by one group (Beck and Lampe, unpublished data). Decompression may be required in irreducible subluxation and severe circumferential cord compression when it is performed in conjunction with posterior occipitocervical or $\mathrm{C} 1-\mathrm{C} 2$ fixation and fusion.

\section{Subaxial spine}

In the subaxial cervical spine (C3-C7), a segmental PADI of $14 \mathrm{~mm}$ or less and more than $3.5 \mathrm{~mm}$ of subaxial subluxation, particularly if there are progressive neurological deficits or functional deterioration, would require decompression and fixation (Castel et al 2001). In the presence of thickened or ossified posterior longitudinal ligaments causing primary anterior cord compression with signal change, an anterior midline "gutter" multi-level vertebrectomy and cage fixation and fusion approach may be required. In the absence of significant anterior compression and in the presence of a pincer compression, thickened and buckled ligamentum flavum, a posterior augmentation laminoplasty and lateral mass fixation is recommended. Cervical laminectomy is reserved for the most severe cases and should be supported by lateral mass or facet screw posterior fixation to avoid latent instability.

\section{Thoracolumbar kyphosis}

Spinal decompression and deformity correction with posterior instrumented fusion is recommended for MPS IVA patients with progressive and symptomatic thoracolumbar kyphosis. The choice of approach, type and extent of fixation varies amongst deformity correction spinal surgeons, but it is generally accepted that a decompression should be supported with instrumentation and fusion. Anterior discectomy and fusion is strongly recommended in patients with rigid kyphosis to augment a posterior fusion which may be insufficient in these cases. Small stature instrumentation is now available for use and is easily applied in the thoracolumbar spine of patients with MPS IVA.

Intraoperative neurophysiological monitoring (IONM)

The selection of a particular intraoperative monitoring modality test depends on the location and type of spine surgery being performed and what needs to be monitored. There are a variety of neurophysiological monitoring tools available, including SSEP, MEP and electromyography (EMG). SSEPs measure electrical sensory input to the CNS and test neural integrity and CNS connectivity to sensory modalities. However, intraoperative standard SSEP techniques only 
assess function of the dorsal column (the lemniscal system). They identify intrinsic acute and chronic changes within the spinal cord, which is helpful for monitoring and serial surveillance. SSEPs are typically used to monitor the spinal cord during complex spine surgery.

EMG is used to determine if a nerve is being irritated or pinched. It is used to monitor nerve output to the muscles in procedures where screws are placed in the middle or lower part of the spine. SSEP is used to double-check that the sensory part of the nerve is functioning correctly.

The transcranial MEP (Tc-MEP) activates motor pathways and produces recordable motor contraction (muscle MEP) and a nerve action potential (D-wave). In spinal surgery, loss of the muscle MEP without more than a $50 \%$ change in the D-wave was associated only with transient neurologic deficit (Sala et al 2006). However, Dwave recording is difficult (Ulkatan et al 2006) and it has been proposed that a reduction in amplitude of $50 \%$ or more should be considered significant (Krammer et al 2009). MEPs are more difficult to obtain and require trained and qualified staff to analyse them. Their use for scoliosis surgery has recently become more established (Stecker 2012). Although IONM (Tc-MEP and SSEP) techniques are well known and have high sensitivity and specificity, there is little published data showing that monitoring actually leads to improved patient outcomes. They provide sensitive and specific indications of neurological injury but have limitations that must be understood. Maintaining a high quality of practice with appropriately trained personnel is critical (Stecker 2012).

\section{Surgical outcomes}

Based on the authors' experience and the few series and case studies available in the literature, short-term post-operative outcomes are generally favourable, with high fusion rates if fusion was performed and varying degrees of neurological improvement (Ain et al 2006; Dalvie et al 2001; Holte et al 1994; Houten et al 2011; Lipson 1977; Ransford et al 1996; Stevens et al 1991). Long-term follow-up is essential for the detection and management of post-surgical complications, which may include late instability below the fusion site and halo pin tract infection. Less known are the long-term outcomes of surgical intervention as there is very limited information on post-operative outcomes beyond 5 years; evidence thus far is mixed (Ain et al 2006; Ransford et al 1996; Svensson and Aaro 1988; White et al 2009). Recurrence of instability appears to develop about 5 to 6 years later below an intact fusion and often with neurological compromise, and this is an important consideration. Approximately half of patients who undergo simple decompression will require revisional surgery (Beck and Lampe, unpublished data). Multiple fusions may be required as a result of progressive instability following a successful fusion (Wraith 1995).

Anaesthetic management

The anaesthetic care of MPS IVA patients presenting for surgery is challenging (Belani et al 1993; McLaughlin et al 2010; Morgan et al 2002; Shinhar et al 2004; Theroux et al 2012; Walker et al 1994). For patients with atlantoaxial instability, it is essential that the head and neck are carefully aligned and that flexion and extension movements are minimized. These physical constraints, including the use of halo immobilization, can lead to difficulties in intubating the trachea. Airways narrowed and rendered tortuous by GAG deposition can cause difficulties with ventilation and intubation. Pulmonary function may be compromised due to upper airway obstruction, restrictive lung disease secondary to thoracic kyphosis/scoliosis and pectus carinatum, and respiratory muscle weakness secondary to myelopathy from chronic spinal cord compression injury. Because these complications increase the risk of perioperative morbidity and mortality, patients with MPS IVA should be managed by experienced anaesthesiologists at centres familiar with MPS disorders. Special considerations for the anaesthetic management of MPS IVA patients are presented below.

\section{Preoperative assessment and planning}

Prior to any surgical procedure that requires sedation or anaesthesia, MPS IVA patients should undergo careful and thorough pulmonary, cardiac and otolaryngology evaluations. Pulmonology consult may include CT of the chest and fluoroscopy of the airway as deemed necessary by the pulmonologist. Any reactive airway disease should be treated aggressively prior to surgery. The use of a single dose of methylprednisolone prophylactically to prevent intraoperative bronchospasm and mucosal swelling of the airway may be considered. Difficult airway equipment and skilled airway personnel should be made readily available.

Preoperative assessment usually includes radiological evaluations such as MRI or CT imaging studies of the cervical spine which may require general anaesthesia in younger patients or patients unable to remain immobile. If appropriate, all efforts should be made to perform these procedures while patients are awake. Allowing a parent to stay by the side of an affected child often encourages younger patients to agree to an 'awake MRI'. Sedation or general anaesthesia becomes necessary when affected children are younger than $\sim 8$ years of age (variations are to be expected based on culture and expectations of parents). When using anaesthesia, one needs to evaluate the risks involved especially with regard to the airway and spinal cord compromise. An anaesthesiologist with experience caring for MPS IVA 
patients is recommended for the care of these patients whether they are receiving sedation or general anaesthesia. Sedation, when skillfully administered by an anaesthesiologist, can often accomplish the task at hand. When spontaneous breathing is poorly tolerated during sedation due to an obstructed upper airway, general anaesthesia with secured airway, using either a laryngeal mask airway (LMA) or endotracheal tube (ETT), is performed. These practices are likely to vary across different institutions and countries.

\section{Intraoperative management}

For neurophysiological monitoring, total intravenous anaesthesia (TIVA) is used to facilitate optimal capture of the potentials. This practice, however, varies and is ultimately decided by each institution based on the recommendations of the neurophysiologists and the anaesthesiologists. TIVA should be considered in view of dose-related alterations in SSEP with volatile anaesthetics. All volatile agents depress evoked potentials. Nitrous oxide alone does not significantly depress SSEPs but added to other volatile agents profoundly depresses amplitude. Sevoflurane and desflurane have less of an effect on SSEPs compared to earlier anaesthetic agents. Inhalational anaesthetics diminish the ability to obtain MEPs and cortical responses from SSEP. However, the use of volatile anaesthetics at less than 1.0 minimum alveolar concentration (MAC) supplemented with remifentanil could be considered during SSEP. Subcortical responses can be monitored in the presence of inhalational anaesthetics using SSEP.

Correct positioning of an MPS IVA patient requires careful alignment of the mastoid process with the clavicle to ensure a neutral position of the neck. The upper airway should be assessed for obstruction as the patient goes through induction of anaesthesia; two-person mask ventilation is often necessary during this period. The use of videolaryngoscopy alone or in combination with fibre optic bronchoscopy is recommended for intubation (Theroux et al 2012). Difficult airway tools such as lighted stylets that are unable to displace soft tissue effectively are best avoided. When significant difficulty is anticipated, awake intubation with local anaesthetic may be considered in conjunction with availability of emergency tracheostomy; use of sedation in such situations should be determined by the clinical judgement of the anaesthesiologist based on the status of the patient airway. Practices vary in different countries with similar standards.

Postoperative extubation and management

Patients are usually kept in the operating room until breathing spontaneously and then extubated in this safe environment. This allows early assessment of neurological status and may reduce airway swelling from gagging on the tube. However, extubation may be delayed and carried out in the intensive care unit if required. The strategy for extubation should consider all factors that could impact the patient's ability to maintain spontaneous respiration and a patent airway, including any difficulties associated with the initial intubation and the intraoperative course, pre-existing respiratory illness, pre-existing myelopathy, and halo placement. Patients should be extubated when fully awake and when neuromuscular blockers have been reversed, and then monitored closely for early signs of upper airway obstruction and oxygen desaturation following extubation. When using narcotic analgesics, careful monitoring of respiratory status is mandatory. A thorough and detailed communication regarding airway management is necessary between the anaesthesiologist and the intensive care physician upon admitting the patient to an intensive care unit. The need for reintubation should be anticipated and accomplished quickly in order to prevent collapse of the airway. Postoperative swelling of buccal mucosa and lips is common due to the prone position and may be reduced by application of steroid cream over these areas.

\section{Future perspectives}

There are currently no guidelines for systematically assessing the extent of spinal involvement in MPS IVA patients, for identifying candidates for surgery, or for evaluating the impact of treatment. Development of a standardized risk stratification system that is based on objective and measurable clinical, neurological, and radiological parameters would be useful for surgical decision-making. A scoring system based on MRI findings has been proposed for evaluating spinal cord involvement in MPS patients (Lachman et al 2010), and a scoring system has been developed for determining the optimal timing of surgery for MPS IVA patients (Möllmann et al 2012). Objective outcome measures and large well-designed studies are needed to determine the efficacy of surgical and medical treatment.

Genotype-phenotype correlations could potentially facilitate risk assessment, predict outcomes, guide treatment strategies, and facilitate the design of new therapies. A p.Gly116Val mutation in GALNS found in a cohort of MPS IVA patients originating from a specific area in Pakistan has been associated with earlier onset and higher incidence of dens hypoplasia, instability and compression (Solanki et al 2010; Solanki et al 2009).

The value of the neurological examination can be increased by defining critical signs and symptoms indicating spinal cord lesions and the risk of irreversible changes. The possible role of electrophysiology needs to be elucidated in further studies. 
Imaging technology is evolving rapidly, and new MRI sequences could enable more sensitive visualization of the spinal cord. These advances could also enable faster and more cost-effective MRI screening and monitoring of MPS IVA patients. Introduction of neurophysiological monitoring in the MRI suite will add safety to dynamic studies in anaesthetized patients that are optimal for assessing instability and effect on cord.

More studies are needed to assess the long-term impact of surgical intervention. Advances in spinal fusion surgery and instrumentation are likely to improve outcomes for MPS IVA patients. The use of recombinant human bone morphogenetic protein-2 (rhBMP-2) is currently being investigated in paediatric patients with MPS, particularly MPS IVA, and initial findings suggest that it enhances fusion rates without bone grafts and leads to reformation or ossification of the dens (Oluigbo and Solanki 2008; Solanki et al 2008).

Enzyme replacement therapy (ERT) for MPS IVA, for which clinical trials are currently underway (http://clinicaltrials. gov), may be a treatment option in the future. Early intervention as reported for MPS VI (Furujo et al 2011; McGill et al 2010) may be able to normalize bone growth and reduce risk of spinal cord compression and spine instability. This will need to be evaluated systematically with regular MRI monitoring before and after initiation of ERT when this treatment approach is considered.

\section{Conclusions}

Spinal involvement is a major cause of disability and death in MPS IVA. Through systematic assessment and management of cervical instability, spinal stenosis and spinal cord compression, irreversible neurological damage may be averted or arrested to improve patient outcomes. It is important to correlate clinical and neurological findings with imaging studies. MRI is the most useful imaging technique for assessing the degree of spinal stenosis and cord compression. Fusion and/or decompression are generally safe and effective surgical interventions for symptomatic patients, but long-term outcomes are unclear. Asymptomatic patients with evidence of cord compression as determined by MRI and/or with evidence of cervical instability may be considered for surgery to prevent permanent spinal cord injury. Any elective surgery requires a skilled anaesthesiologist who has experience managing patients with small airways and cervical spine instability. Standardized assessments and routine outcome measures should be developed and implemented to enhance patient care in MPS IVA.

Acknowledgements This manuscript was conceived at a summit sponsored by BioMarin Pharmaceutical Inc. (BioMarin). BioMarin provided editorial and administrative assistance as well as critical reviews throughout the drafting of this manuscript.
Competing interests G. A. Solanki, K. W. Martin and M. C. Theroux have each received speaker's honorarium and travel support from BioMarin Pharmaceutical Inc. (BioMarin). C. Lampe has received speaker's fees, consulting fees, travel support and research grants from BioMarin. K. K. White has received honoraria, research grants and travel support from BioMarin, and is an investigator in MPS IVA clinical trials. R. Shediac is an employee and shareholder of BioMarin. C.G. Lampe and W. G. Mackenzie have received travel support from BioMarin. M. Beck has received speaker's fees, consulting fees, travel support and unrestricted research grants from Biomarin. C. J. Hendriksz has received consulting fees, symposium support for himself and team personnel, and research grants from BioMarin, and has also been an investigator in MPSIVA clinical trials. P. R. Harmatz has provided consulting support to BioMarin, has received research grants, speaker's honorarium and travel support from BioMarin, and is an investigator in MPS IVA clinical trials.

Open Access This article is distributed under the terms of the Creative Commons Attribution License which permits any use, distribution, and reproduction in any medium, provided the original author(s) and the source are credited.

\section{References}

Ahmed R, Traynelis VC, Menezes AH (2008) Fusions at the craniovertebral junction. Childs Nerv Syst 24:1209-1224

Ain MC, Chaichana KL, Schkrohowsky JG (2006) Retrospective study of cervical arthrodesis in patients with various types of skeletal dysplasia. Spine (Phila Pa 1976) 31:E169-174

Ashraf J, Crockard HA, Ransford AO, Stevens JM (1991) Transoral decompression and posterior stabilisation in Morquio's disease. Arch Dis Child 66:1318-1321

Beighton P, Craig J (1973) Atlanto-axial subluxation in the Morquio syndrome. Report of a case. J Bone Joint Surg Br $55: 478-481$

Belani KG, Krivit W, Carpenter BL et al (1993) Children with mucopolysaccharidosis: perioperative care, morbidity, mortality, and new findings. J Pediatr Surg 28:403-408, discussion 408-410

Blaw ME, Langer LO (1969) Spinal cord compression in MorquioBrailsford's disease. J Pediatr 74:593-600

Boden SD, Dodge LD, Bohlman HH, Rechtine GR (1993) Rheumatoid arthritis of the cervical spine. A long-term analysis with predictors of paralysis and recovery. J Bone Joint Surg Am 75:1282-1297

Boor R, Miebach E, Bruhl K, Beck M (2000) Abnormal somatosensory evoked potentials indicate compressive cervical myelopathy in mucopolysaccharidoses. Neuropediatrics 31:122-127

Brailsford JF (1929) Chondro-osteo-dystrophy. Roentgenographic and clinical features of a child with dislocation of vertebrae. Am J Surg 7:404-410

Bransford RJ, Lee MJ, Reis A (2011) Posterior fixation of the upper cervical spine: contemporary techniques. J Am Acad Orthop Surg 19:63-71

Brooks AL, Jenkins EB (1978) Atlanto-axial arthrodesis by the wedge compression method. J Bone Joint Surg Am 60:279-284

Castel E, Benazet JP, Samaha C, Charlot N, Morin O, Saillant G (2001) Delayed closed reduction of rotatory atlantoaxial dislocation in an adult. Eur Spine J 10:449-453

Claybrooks R, Kayanja M, Milks R, Benzel E (2007) Atlantoaxial fusion: a biomechanical analysis of two $\mathrm{C} 1-\mathrm{C} 2$ fusion techniques. Spine J 7:682-688

Clemente CD (2010) Clemente's anatomy dissector. Lippincott Williams \& Wilkins, Baltimore

Dalvie S, Skinner J, Vellodi A, Noorden MH (2001) Mobile thoracolumbar gibbus in Morquio type A: the cause of paraparesis and its management. J Pediatr Orthop B 10:328-330 
Davison JE, Kearney S, Horton J, Foster K, Peet AC, Hendriksz CJ (2012) Intellectual and neurological functioning in Morquio syndrome (MPS IVa). J Inherit Metab Dis Jan 10

Elgafy H, Potluri T, Goel VK, Foster S, Faizan A, Kulkarni N (2010) Biomechanical analysis comparing three $\mathrm{C} 1-\mathrm{C} 2$ transarticular screw salvaging fixation techniques. Spine (Phila Pa 1976) 35:378-385

Furujo M, Kubo T, Kosuga M, Okuyama T (2011) Enzyme replacement therapy attenuates disease progression in two Japanese siblings with mucopolysaccharidosis type VI. Mol Genet Metab 104:597-602

Gallie WE (1939) Fractures and dislocations of the cervical spine. Am J Surg 46:495-499

Goel A (2004) Treatment of basilar invagination by atlantoaxial joint distraction and direct lateral mass fixation. J Neurosurg Spine 1:281-286

Gunnarsson T, Massicotte EM, Govender PV, Raja Rampersaud Y, Fehlings MG (2007) The use of C1 lateral mass screws in complex cervical spine surgery: indications, techniques, and outcome in a prospective consecutive series of 25 cases. J Spinal Disord Tech 20:308-316

Haid RW Jr (2001) C1-C2 transarticular screw fixation: technical aspects. Neurosurgery 49:71-74

Harms J, Melcher RP (2001) Posterior C1-C2 fusion with polyaxial screw and rod fixation. Spine (Phila Pa 1976) 26:2467-2471

Harnsberger HR, Osborn AG, Ross JS et al (2006) Diagnostic and surgical imaging anatomy: brain, head \& neck, spine. Amirsys, Salt Lake City

Helgeson MD, Lehman RA Jr, Dmitriev AE et al (2011) Accuracy of the freehand technique for 3 fixation methods in the C-2 vertebrae. Neurosurg Focus 31:E11

Hendriksz CJ, Al-Jawad M, Berger KI et al (2012) Clinical overview and treatment options for non-skeletal manifestations of mucopolysaccharidosis type IVA. J Inherit Metab Dis doi: 10.1007/ s10545-012-9459-0

Henriques T, Cunningham BW, Olerud C et al (2000) Biomechanical comparison of five different atlantoaxial posterior fixation techniques. Spine (Phila Pa 1976) 25:2877-2883

Holte DC, Rogers MA, Ransford AO, Crockard HA (1994) Thoracic spinal cord compression in Morquio-Brailsford's disease. NeuroOrthopedics 16:31-37

Horovitz DD, Magalhaes Tde S, Pena e Costa A et al (2011) Spinal cord compression in young children with type VI mucopolysaccharidosis. Mol Genet Metab 104:295-300

Houten JK, Kinon MD, Goodrich JT (2011) Morquio's syndrome and craniocervical instability. Pediatr Neurosurg 47:238-240

Hughes DG, Chadderton RD, Cowie RA, Wraith JE, Jenkins JP (1997) MRI of the brain and craniocervical junction in Morquio's disease. Neuroradiology 39:381-385

Kessler JT (1975) Congenital narrowing of the cervical spinal canal. J Neurol Neurosurg Psychiatry 38:1218-1224

Kopits SE (1976) Orthopedic complications of dwarfism. Clin Orthop Relat Res: $153-179$

Krammer MJ, Wolf S, Schul DB, Gerstner W, Lumenta CB (2009) Significance of intraoperative motor function monitoring using transcranial electrical motor evoked potentials (MEP) in patients with spinal and cranial lesions near the motor pathways. $\mathrm{Br} \mathrm{J}$ Neurosurg 23:48-55

Lachman R (2007) Taybi and Lachman's radiology of syndromes, metabolic disorders, and skeletal dysplasias. Mosby, Philadelphia

Lachman R, Martin KW, Castro S, Basto MA, Adams A, Teles EL (2010) Radiologic and neuroradiologic findings in the mucopolysaccharidoses. J Pediatr Rehabil Med 3:109-118

Lee SH, Kim ES, Sung JK, Park YM, Eoh W (2010) Clinical and radiological comparison of treatment of atlantoaxial instability by posterior $\mathrm{C} 1-\mathrm{C} 2$ transarticular screw fixation or $\mathrm{C} 1$ lateral massC2 pedicle screw fixation. J Clin Neurosci 17:886-892
Lipson SJ (1977) Dysplasia of the odontoid process in Morquio's syndrome causing quadriparesis. J Bone Joint Surg Am 59:340 344

Lustrin ES, Karakas SP, Ortiz AO et al (2003) Pediatric cervical spine: normal anatomy, variants, and trauma. Radiographics 23:539-560

Mackenzie WG, Dhawale AA, Demczko MM et al (2013) Flexionextension cervical spine MRI in children with skeletal dysplasia: is it safe and effective? J Pediatr Orthop 33:91-98

Madawi AA, Casey AT, Solanki GA, Tuite G, Veres R, Crockard HA (1997) Radiological and anatomical evaluation of the atlantoaxial transarticular screw fixation technique. J Neurosurg 86:961-968

McDonald A, Steiner R, Kuehl K, Turbeville S (2010) Clinical utility of endurance measures for evaluation of treatment in patients with mucopolysaccharidosis VI (Maroteaux-Lamy syndrome). J Pediatr Rehabil Med 3:119-127

McGill JJ, Inwood AC, Coman DJ et al (2010) Enzyme replacement therapy for mucopolysaccharidosis VI from 8 weeks of age-a sibling control study. Clin Genet 77:492-498

McLaughlin AM, Farooq M, Donnelly MB, Foley K (2010) Anaesthetic considerations of adults with Morquio's syndrome a case report. BMC Anesthesiol 10:2

Möllmann C, Lampe CG, Müller-Forell W et al (2012) Indications for craniocervical spinal cord decompression in patients with mucopolysaccharidosis IV A (Morquio A syndrome): development of a scoring system to determine optimal timing of surgery, Manuscript submitted

Montano AM, Tomatsu S, Gottesman GS, Smith M, Orii T (2007) International Morquio A Registry: clinical manifestation and natural course of Morquio A disease. J Inherit Metab Dis 30:165174

Morgan KA, Rehman MA, Schwartz RE (2002) Morquio's syndrome and its anaesthetic considerations. Paediatr Anaesth 12:641-644

Morquio L (1929) Sur une forme de dystrophie osseuse familiale. Arch Med Enf Paris 32:129-135

Müller-Forell W, Schulze Frenking G, Amraoui Y, Beck M (2007) Mucopolysaccharidoses (MPS). Clinical and Neuroradiological Aspects of the Different Types. Clinical Neuroradiology $17: 141-158$

Nelson J (1997) Incidence of the mucopolysaccharidoses in Northern Ireland. Hum Genet 101:355-358

Nelson J, Crowhurst J, Carey B, Greed L (2003) Incidence of the mucopolysaccharidoses in Western Australia. Am J Med Genet A $123 \mathrm{~A}: 310-313$

Northover H, Cowie RA, Wraith JE (1996) Mucopolysaccharidosis type IVA (Morquio syndrome): a clinical review. J Inherit Metab Dis 19:357-365

Oluigbo CO, Solanki GA (2008) Use of Recombinant Human Bone Morphogenetic Protein-2 to Enhance Posterior Cervical Spine Fusion at 2 Years of Age: Technical Note. Pediatr Neurosurg 44:393-396

Ransford AO, Crockard HA, Stevens JM, Modaghegh S (1996) Occipito-atlanto-axial fusion in Morquio-Brailsford syndrome. A ten-year experience. J Bone Joint Surg Br 78:307-313

Sala F, Palandri G, Basso E et al (2006) Motor evoked potential monitoring improves outcome after surgery for intramedullary spinal cord tumors: a historical control study. Neurosurgery 58:1129-1143, discussion 1129-1143

Shinhar SY, Zablocki H, Madgy DN (2004) Airway management in mucopolysaccharide storage disorders. Arch Otolaryngol Head Neck Surg 130:233-237

Shukla D, Arvind S, Devi BI (2011) Myelopathy in a dwarf: a case of Morquio's syndrome without odontoid hypoplasia. Neurol India 59:126-127

Solanki GA, Crockard HA (1999) Peroperative determination of safe superior transarticular screw trajectory through the lateral mass. Spine (Phila Pa 1976) 24:1477-1482 
Solanki GA, Madawi AA, Casey ATH, Crockard HA (1996) Morphometric analysis of the axis, with particular reference to posterior screw fixations. J Neurol Neurosurg Psychiatry 61:550-551

Solanki G, Vijay S, Chakrapani A, Hendriksz C (2008) Progressive spinal instability in MPS - Use of recombinant human bone morphogenetic protein-2 (RhBMP-2) to augment posterior spine fusion. J Inherit Metab Dis 31:435P

Solanki GA, Ekanayake J, Roy D, Vijay S, Hendriksz C, Chakrapani A (2009) Morquio-Brailsford p.Gly116Val genotype: a previously unreported mutation. Does it lead to severe spinal involvement? Childs Nerv Syst 25:1345-1346

Solanki GA, Ekanayake J, Roy D, Hendriksz C, Vijay S, Chakrapani A (2010) P.GLY116VAL mutation in MorquioBrailsford syndrome: evidence for severe spinal involvement. Childs Nerv Syst 26:566

Stecker MM (2012) A review of intraoperative monitoring for spinal surgery. Surg Neurol Int 3:S174-187

Stevens JM, Kendall BE, Crockard HA, Ransford A (1991) The odontoid process in Morquio-Brailsford's disease. The effects of occipitocervical fusion. J Bone Joint Surg Br 73:851858

Svensson O, Aaro S (1988) Cervical instabiity in skeletal dysplasia. Act Orthop Scand 59:66-70
Theroux MC, Nerker T, Ditro C, Mackenzie WG (2012) Anesthetic care and perioperative complications of children with Morquio syndrome. Paediatr Anaesth 22:901-907

Tomatsu S, Montano AM, Nishioka T et al (2005) Mutation and polymorphism spectrum of the GALNS gene in mucopolysaccharidosis IVA (Morquio A). Hum Mutat 26:500-512

Tomatsu S, Montano AM, Oikawa H et al (2011) Mucopolysaccharidosis type IVA (Morquio A disease): clinical review and current treatment. Curr Pharm Biotechnol 12:931-945

Torg JS, Corcoran TA, Thibault LE et al (1997) Cervical cord neurapraxia: classification, pathomechanics, morbidity, and management guidelines. J Neurosurg 87:843-850

Ulkatan S, Neuwirth M, Bitan F, Minardi C, Kokoszka A, Deletis V (2006) Monitoring of scoliosis surgery with epidurally recorded motor evoked potentials (D wave) revealed false results. Clin Neurophysiol 117:2093-2101

Walker RW, Darowski M, Morris P, Wraith JE (1994) Anaesthesia and mucopolysaccharidoses. A review of airway problems in children. Anaesthesia 49:1078-1084

White KK, Steinman S, Mubarak SJ (2009) Cervical stenosis and spastic quadriparesis in Morquio disease (MPS IV). A case report with twenty-six-year follow-up. J Bone Joint Surg Am 91:438-442

Wraith JE (1995) The mucopolysaccharidoses: a clinical review and guide to management. Arch Dis Child 72:263-267 